\title{
Determination of Basic Reservoir Parameters in Shale Formations as a Solution of Inverse Problem in the Computer Assisted History Matching of their Simulation Models. Part I - Introduction to Methodology and Initial Tests
}

\begin{abstract}
The problem of effective reservoir characterization of shale formations was addressed in the paper as the implementation of inverse problem applied to the history matching process of the formations simulation models. An advanced method of inverse problem solution was proposed based on the combination of stochastic and deterministic approaches. The method was than tested using simulation models generated for the case of a realistic shale formations discovered and tested in Poland.
\end{abstract}

Key words: shale formations, reservoir simulation models, inverse problem, optimization methods, particle swarm optimization.

\section{Rozpoznanie istotnych parametrów formacji łupkowych poprzez rozwiązanie problemu odwrotnego metodą wspomaganej komputerowo kalibracji modeli symulacyjnych. Część 1 - wprowadzenie do metodyki i wstępne testy}

\begin{abstract}
W pracy podjęto zagadnienie charakterystyki formacji łupkowej pod kątem lepszego rozpoznania istotnych parametrów formacji. Zaproponowano podejście bazujące na komputerowo wspomaganej kalibracji modelu symulacyjnego takiej formacji, jako metodzie rozwiązania problemu odwrotnego. W metodzie tej zaimplementowano kombinację nowoczesnych technik optymalizacyjnych o charakterze stochastycznym i deterministycznym. Analizowana metoda została przedstawiona na uprzednio skonstruowanym, dynamicznym modelu wybranej formacji łupkowej.
\end{abstract}

Słowa kluczowe: struktury łupkowe, symulacyjne modele złożowe, problem odwrotny, metody optymalizacyjne, optymalizacja rojem cząstek.

\section{Introduction}

The basic problem of construction and effective utilisation of reservoir simulation models for reservoir forecasting, is the issue of correct identification of reservoir parameters, including the parameters of producing wells [9]. Both in conventional and unconventional hydrocarbon reservoirs the direct measurements of these parameters are generally not sufficiently complete, or fully reliable, so that they can be directly used to construct reliable simulation models. Therefore, an indispensable element of the work with such models, is their calibration, being one of the most labour-intensive and complex stages of reservoir modelling.

The aforementioned problem is particularly important for unconventional reservoirs (including shale formations) due to the typically poorer identification of characteristics of such reservoirs and in particular the characteristics of their completion. The problem of identifying reliable 
parameters of the simulation model on the basis of exploitation data (well tests, initial production) in the model calibration process (history matching), is an example of the inverse problem [2], where based on the results of the model response (simulation results) and their comparison with measurement data (test data and/or production data), the correct parameterisation of the model is provided. Such a problem (as mentioned above) is generally ambiguous (i.e. ill-posed), even with the application of limits concerning the extent of parameter variability and their mutual correlation (including spatial correlation).

When expressed quantitatively the compliance of the model results with measurement data in the form of the objective function (being the measure of discrepancies), the ambiguity of the inverse problem is expressed by multiple local minima of this function and the solution of the problem is equivalent to finding the global minimum of the objective function. Due to the lack of universal methods for global minimisation of such a function, the solution of the above problem is most frequently reduced to "manual" tracing of function values and modification of model parameters by using engineering knowledge and experience of persons conducting the calibration process.

In this paper, we propose a method for solving the inverse problem based on the "computer assisted history matching" ("computer-assisted calibration") of the model with application of a combination of modern stochastic and deterministic methods described in the following chapters of the paper. The proposed method to solve the inverse problem was tested initially on the so-called, "test functions" and then on the actual example of Polish shale formations drilled in and tested through a single vertical well-bore. For this purpose, a static model of the formation was constructed with typical parameters describing the flow dynamics and results of tests (test production) carried out in the aforementioned well bore.

At first this model was calibrated in a conventional manner and then by using the proposed method. Both calibration processes and their accuracy and execution time have been compared, pointing to the advantages of applying the proposed method. The process of computer-assisted calibration of the simulation model, was carried out by means of in-house software, with the application of the Eclipse simulator [10].

\section{Method of solution}

The proposed method of solution of the presented inverse problem is based on four mathematical and numerical techniques creating a hybrid optimization method. Short characteristics of selected computational techniques are presented below.

\section{Particle Swarm Optimization}

In particle swarm optimization $[1,4-7]$ the candidate solutions (called particles) cooperate with each other to find the optimum solution. During the optimization process, each particle changes its position in the search space of solutions by determining the velocity vector. This vector is modified with the use of information, about the history of exploration, both of a given particle and the remaining particles of the swarm.

The method can be described by the following formulas:

position: $x_{t+1}^{i}=x_{t}^{i}+v_{t+1}^{i}$

velocity: $v_{t+1}^{i}=\omega v_{t+1}^{i}+c_{1} r_{1}\left(p_{t}^{i}-x_{t}^{i}\right)+c_{2} r_{2}\left(p_{t}^{g}-x_{t}^{i}\right)$

In each iteration step $(t)$ the position of a particle in the multidimensional space $\left(x_{t}^{i}\right)$ is modified in accordance with the formula (1) through the velocity vector $v_{t+1}^{i}$ (2). The velocity vector in step $t+1$ is the function of the previous position of the particle $\left(x_{t}^{i}\right)$ and the velocity vector $\left(v_{t+1}^{i}\right)$ which, in turn, depends on the best solution found by that particle $\left(p_{t}^{i}\right)$ and the best solution found by all particles $\left(p_{t}^{g}\right)$.
The remaining values appearing in formula (2) are: $\omega$-fixed or a variable parameter of inertia, $r_{1}, r_{2}$ - random numbers from the range $(0 \div 1), c_{1}, c_{2}$ - scaling parameters (variable or fixed).

According to the above formulas, each particle of the swarm explores the search space of solutions by modifying the position based on its best solution $\left(p_{t}^{i}\right)$ and by using the information on the best solution in the swarm $\left(p_{t}^{g}\right)$. The scaling factors $c_{1}, c_{2}$ allow to control the impact of individual elements of the velocity vector on the solution. If $c_{1}=0$, the particle uses exclusively the information on the best solution of the swarm. For $c_{2}=0$ the particle seeks solutions independently, not taking into account the solutions obtained by other particles. It should be noted that a number of modifications of the particle swarm optimization can be found in specialist literature. However, the most commonly encountered form of it was described above.

\section{Latin hypercube sampling}

Sampling of the Latin cube [3] belongs to the group of techniques of experimental design and is one of the most effective methods of generating random samples, based on the probability density function. The idea of the method is based on the division of random space into separable subspaces by dividing ranges of variation of each component, in the $N$-dimensional random space, into a specified number of 
sub-intervals. Then a specific number of samples is generated in such a way as to obtain one sampling per sub-space constructed according to the principle of combinatorics in all dimensions of problem space. Sampling per sub-space of the random space are selected using the inverse cumulative distribution function of the probability distribution of single components of the random vector, where a different probability distribution can be applied on each component.

\section{The Nelder-Mead method}

The Nelder-Mead simplex method [8] belongs to a group of non-gradient optimization methods utilising (in the optimization process) exclusively the values of the objective function. The method is based on the notion of a simplex, which is a geometrical figure maintaining a set of $N+1$ points in the $N$-dimensional space (a triangle is the simplex in the $R^{2}$ space, a tetrahedron in the $R^{3}$ space, etc.). In the exploration of search space, the simplex utilises the values of the optimized function in three selected points: the best point, the worst point, the second worst point where it selects the direction, opposite to the direction of the greatest increase in the value of the function.

\section{Lévy flight}

The Lévy flight [11] must be understood as a stochastic Markov process, which involves searching the space of variables, where, after a sufficiently large number of steps, their lengths can be described by the Lévy stable distribution. For numerical purposes, the Lévy distribution is usually defined through utilisation of the so-called, Mantegna's algorithm based on a combination of two random variables with normal distribution with designated average values and standard deviation. In the constructed algorithm the change of position of a particle, called the "Lévy jump" is determined by using the following formula:

$$
x_{t+1}^{i}=x_{t}^{i}+0.01 v\left(x_{t}^{i}-p_{t}^{i}\right) z
$$

where $\boldsymbol{z}$ is a random variable with normal probability distribution, $v$ is a number generated by means of the Lévy distribution, $p_{t}^{i}$ is the best solution found by a given particle.

\section{Hybrid algorithm}

The prototype of the method for solving the inverse problem operates according to the following scheme:

1. Downloading the operating parameters of the program (observational data, control parameters, parameters of the optimization method, optimization parameters of the model, their ranges of variability and definitions of the values optimized).

2. Random selection by means of the Latin hypercube sampling of the "swarm" of particles (i.e. solutions from which each is represented by the simulation model).

3. Selection of the best solutions for further optimization.

4. Initialisation of the main optimization loop.

5. Modification of solutions in accordance with the formula of the particle swarm optimization, taking into account the "Lévy jump".

6. Determining the value of the objective functions for each of the "swarm" models.

7. Improving the best solution by the Nelder-Mead algorithm.

8. Checking the conditions for finishing the optimization.

If the condition for finishing optimization has not been fulfilled - return to step 4 .

The presented procedure is performed until the moment of reaching the condition for finishing the calculation, e.g. reaching the specific number of performed simulations (calculations of the objective function) or obtaining the set accuracy of restoring measurement data. The constructed algorithm was subjected to tests of convergence by the use of the De Jong tests. De Jong tests rely on examining the convergence of optimization algorithms on an example of the defined analytic functions with known extremes.

Fig. 1 shows the results of the sample test of convergence for the Generalised Rosenbrock's Function. The graph below depicts the value of the objective function (marked by OF) demonstrating discrepancy between the observational data and the result of optimization.

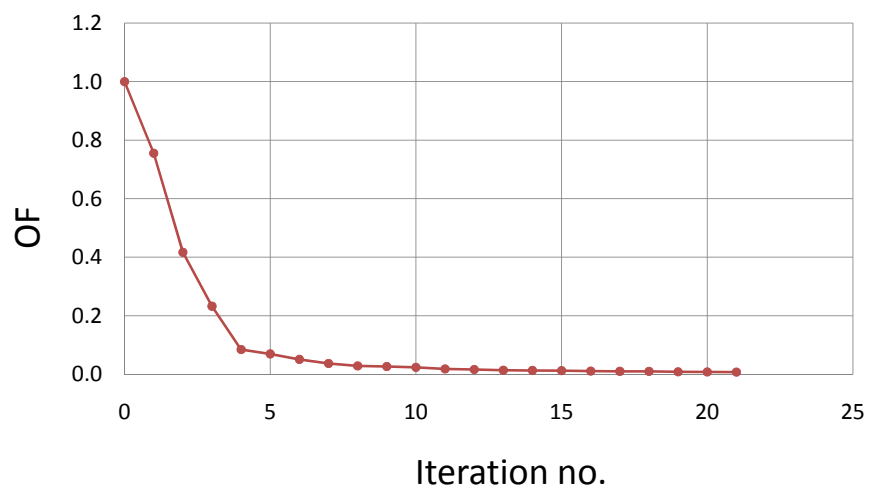

Fig. 1. Test of convergence on the example of Generalised Rosenbrock's Function

\section{The construction and verification of the dynamic model of Polish shale formations}

For the purpose of further testing of the proposed method, a simulation model of real shale formation was constructed and verified. The area of the geological model (Fig. 2) has dimensions of about $12 \times 11.5 \mathrm{~km}$ and average thickness 


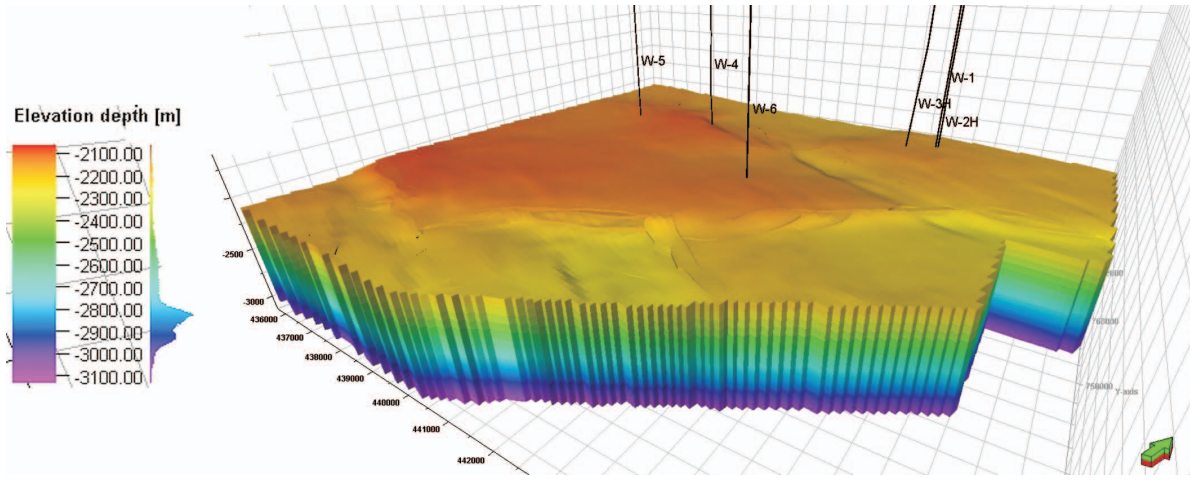

Fig. 2. Demonstration of 3D view of the geological model of selected shale formation fracture is modelled by giving its aperture and the number of blocks surrounding it with the logarithmic increase of their width.

Finally (after modifications and limitations of the grid) the static model is characterized by the following dimensions of the grid of blocks: $33 \times 28 \times 9$ and the area of about $17 \mathrm{~km}^{2}$ (about $3.2 \times 5.3 \mathrm{~km}$ ). The static model was supplemented with the following elements: thermo- exceeding $800 \mathrm{~m}$. The elaboration was limited to the modelling of production from one of the wells: $\mathrm{W}-1$ which contains a complete set of exploitation data in the form of reports concerning cleanout operations and well bore measurements. Due to the fact that the full area of the geological model is characterised by a very large thickness, the model has been modified in the following manner:

- the thickness has been limited to F1 and F2 formations (Fig. 3) in which the highest value of TOC (Total Organic Carbon) occurred. The other layers were found to be inefficient and not participating in the exploitation of the structure,

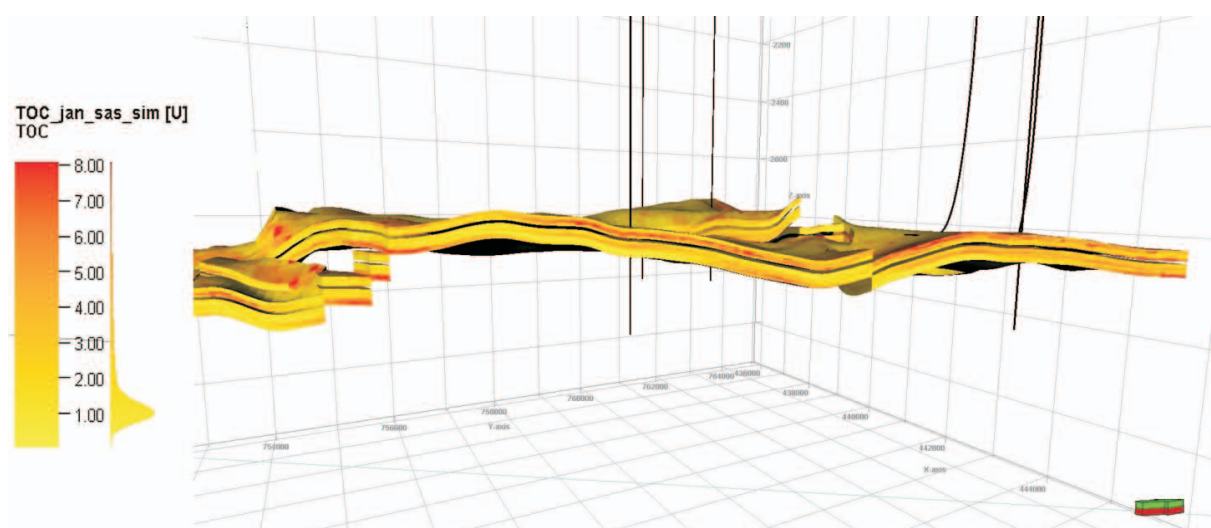

Fig. 3. Demonstration of 3D view of the geological model of analysed shale formation. The selected F1 and F2 formations. TOC content dynamic model of the reservoir fluid and reservoir water, transport properties of reservoir fluid and reservoir water, the parameters of hydro-fracture and secondary fractures with the possible inclusion of fracture dynamics.

The reservoir-fluid model was constructed by means of the PVTSim program, in which the composition of the fluid was recombined on the basis of the stock tank liquid sample subjected to distillation, by the Engler Method, with gas composition (determined by way of the chromatographic test) of the gas obtained from the W-1 well bore. During the recombination process, this fluid was calibrated to the lowest gas/oil ratio which occurred during well production test. The obtained parameters of the reservoir-fluid model (recombined and calibrated) are the following: $\mathrm{GOR}=169.7 \mathrm{Sm}^{3} / \mathrm{Sm}^{3}$, $\rho_{o}=0.81 \mathrm{~g} / \mathrm{cm}^{3}\left(15^{\circ} \mathrm{C}\right), P_{\text {sat }}=210 \mathrm{bar}$, $T_{\text {sat }}=84^{\circ} \mathrm{C}, \mathrm{FVF}=1.54 @ P_{\text {sat }}, T_{\text {sat }}$.

Due to the lack of relevant data, the typical relative permeability curves have been applied concerning transport properties of reservoir fluids occurring in this type of rocks. However, values of parameters describing these curves (in fractures or in a matrix) and the values of other parameters of hydro-fracture or secondary fractures

- the area of the dynamic model has been limited to the area of $\mathrm{W}-1$ where the faults located in the vicinity have been assumed as natural boundaries.

After determining the model area, the geometry of its grid was modified taking into account the hydrofracture of the aperture of $5 \mathrm{~mm}$ (Fig. 4). The proposed new grid of the model is the so-called, Tartan Grid in which the

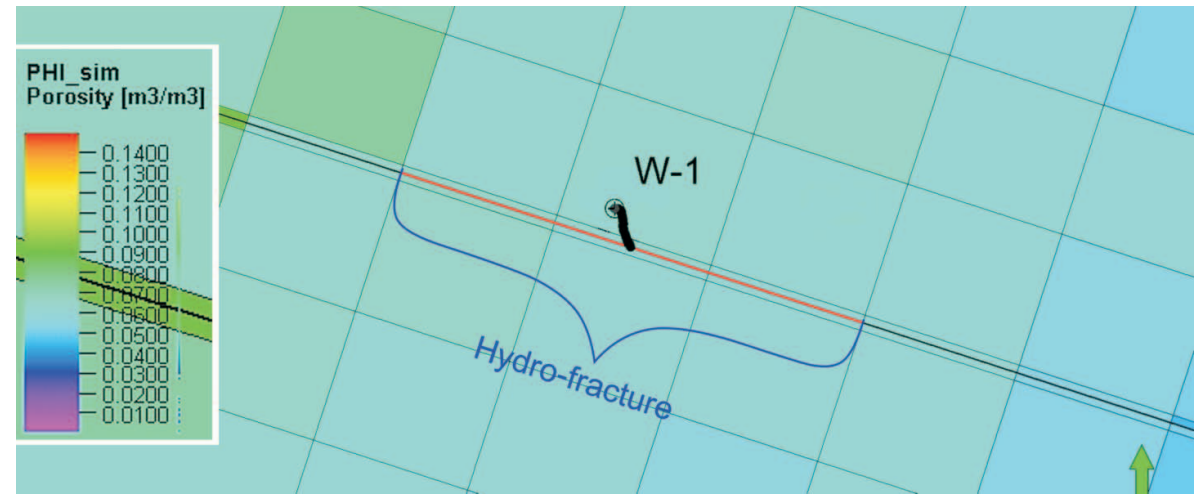

Fig. 4. The new grid of model encompassing hydro-fracture 
were subjected to calibration, the results of which have been presented below. The calibration process also involved the permeability of the matrix due to erroneous measurements.

During calibration of the model, adjustments were made concerning static bottom-hole pressures (measured or calculated from wellhead pressures) including cumulative fluid outflow. The period of operation of the W-1 well was divided into two stages, i.e. fluid removal with nitrogen and pumping and for that reason certain pressure measurement values might be poorly reliable. The quality of the "manual" calibration of the model in the form of comparison of

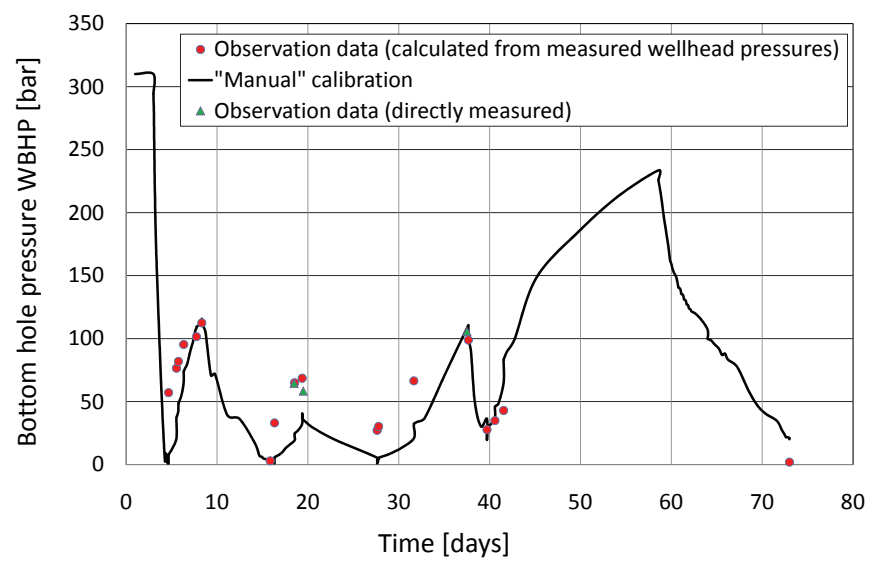

Fig. 5. Calibration of the model. The W-1 well. Pressure at well bottom

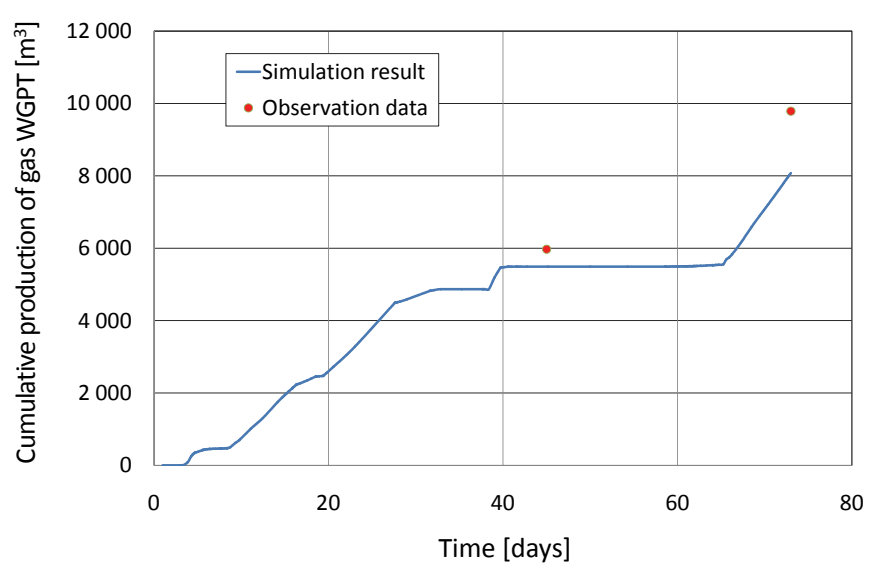

Fig. 7. Calibration of the model. The W-1 well. Cumulative production of gas simulation results with measurement data have been presented in Fig. 4-7.

The model after calibration depicts the production of oil and water (Fig. 6 and 8) and correctly reflects the course of static bottom-hole pressures (Fig. 5). However, cumulative gas production (Fig. 7) is presented in the weakest manner reflecting a discrepancy which increases over time. When the phase of fluid extrusion with nitrogen is finished, the discrepancy is equal to several percent and at the end of simulation it reaches $20 \%$. This may be caused by too low gas/oil ratio measured during the pumping phase.

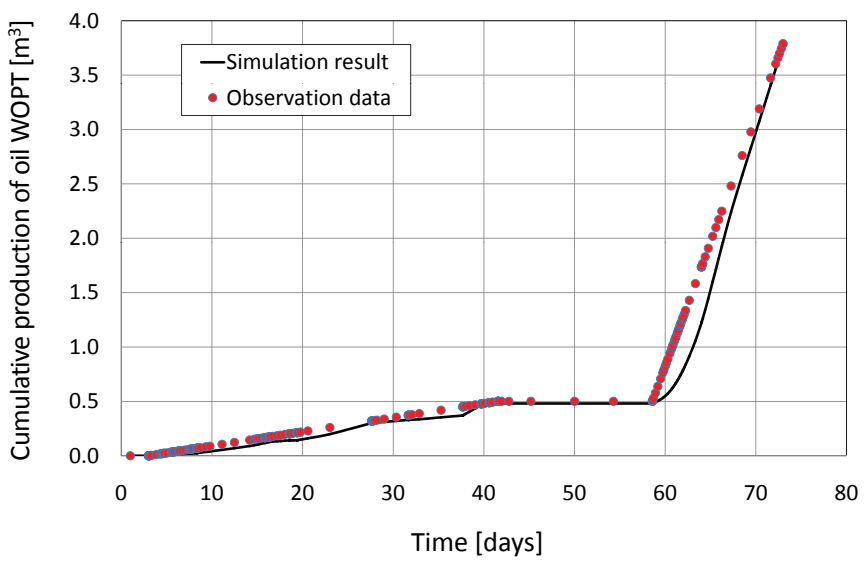

Fig. 6. Calibration of the model. The W-1 well. Cumulative production of oil

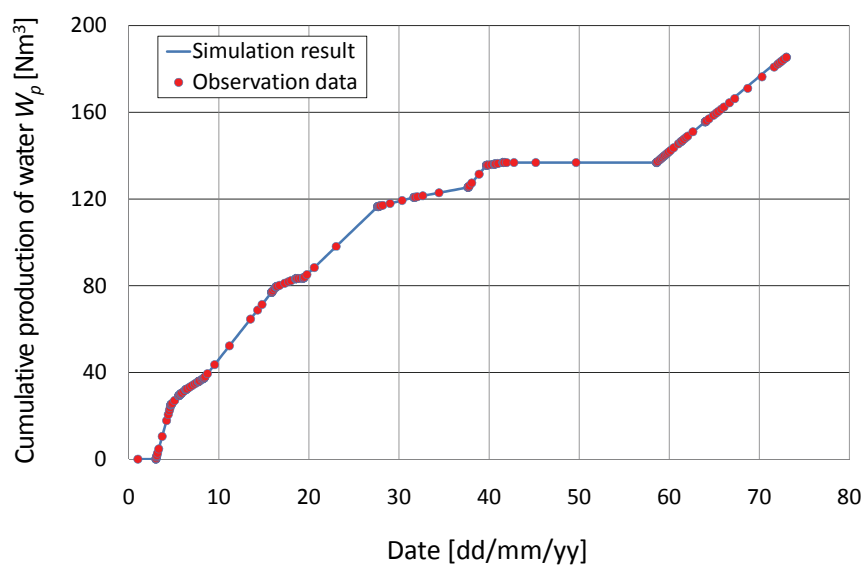

Fig. 8. Calibration of the model. The W-1 well. Cumulative production of water

\section{Test methods based on the actual shale formations method}

The test consisted in the application of the optimization algorithm, designed for the purpose of determining missing parameters of the simulation model (or not exactly determined parameters) and comparing the results with those obtained by way of "manual" calibration. The following parameters of the model were set down: permeability of the matrix, permeability of secondary fractures, permeability and porosity of hydraulic fractures, skin factor, coefficients of productivity and coefficient of fracture-matrix coupling $(\sigma)$. In total, ten simulation model parameters were calibrated. Preliminary estimation of sought parameter values concerning their acceptable ranges was determined on the basis of available data.

In reference to the measure of quality of problem solving (the efficiency of solving the inverse problem), there 
was compliance of measurement data with the results of simulation, for the assumed reference values, i.e. cumulative oil production, WOPT (Fig. 9), cumulative gas production, WGPT (Fig. 10), measurements of bottom-hole pressure, WBHP, during the well production test (Fig. 11).

The results presented do not differ significantly from the results obtained through calibration, by way of traditional methods. They indicate the effectiveness of the proposed method also in the case of real simulation model. However, the run-time of reaching the solution by the proposed method amounted to about ten hours, compared to the time of several days needed for manual calibration.

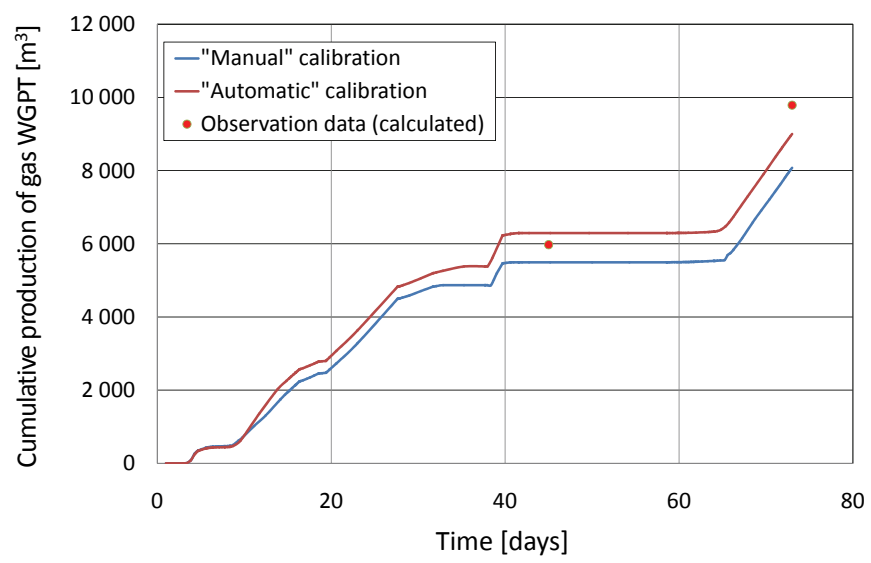

Fig. 10. Cumulative production of gas. Measurements vs. model results after calibration

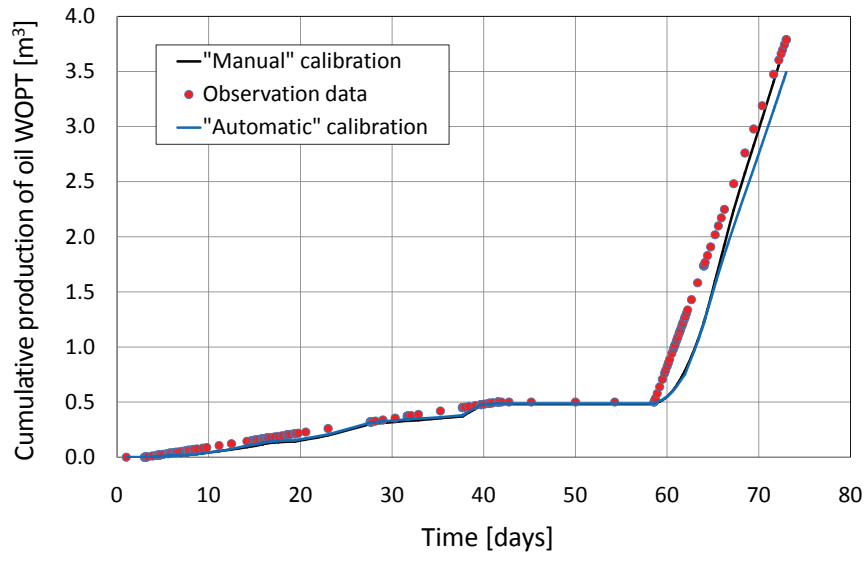

Fig. 9. Cumulative production of oil. Measurements vs. model results after calibration

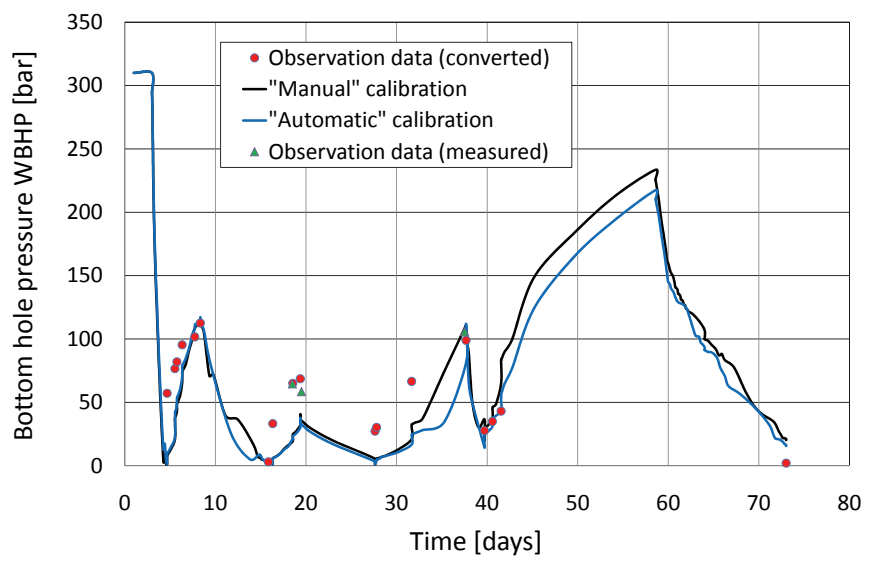

Fig. 11. Bottom-hole pressure. Measurements vs. model results after calibration

\section{Summary}

1. The present paper has shown the proposal of a method using calibration solution of the inverse problem in the form of a hybrid optimization method, encompassing the following mathematical and numerical methods/techniques:

- Latin Hypercube Sampling - effective method of generating random samples from the probability density function for components in the multidimensional space,

- Particle Swarm Optimization - universal method of optimizing the functions of several variables belonging to a group of multi-agent optimization methods,

- Simplex Method or Nelder-Mead Method - deterministic optimization method for functions of several variables without the use of derivatives,
- Random walk according to Lévy distribution (called the "Lévy flight") - method of searching the space of solutions, using Lévy statistical distribution in order to generate the steps for solution space search.

2. In reference to the proposed method, a numerical prototype has been constructed for the calibration inverse problem, based on reservoir simulation and the final numerical procedure;

3. Tests of convergence of the constructed algorithm were carried out. The tests included verification of convergence of the proposed method on the example of analytical test functions (the so-called "benchmark functions") and the actual simulation model of shale formations.

\section{Conclusions}

1. Due to the nature of the problem being solved (poorly-conditioned inverse problem) the proposed algorithm combines traditional optimization methods with methods utilising stochastic optimization techniques. Such a solution is aimed at constructing an efficient algorithm, both in the case of global optimization (efficient searching through multidimensional space of solutions) and local optimization resistant to the phenomenon of "premature 
convergence" in other words, the loss of convergence of the algorithm as a result of achieving a local minimum.

2. Algorithm's ability to correct results in a fast and continuous way, appears to be more important than the answer to the question of whether it is able to find a global optimum. This is the result of the specific nature of the problem being solved. In the case of shale formations, due to the insufficient identification and shortage of laboratory test results (concerning in complete formation characterization), we often do not know the approximate variability ranges of the near-well zone fracture. In addition, we possess sparse observational data which constitutes the basis for quality assessment of solutions generated by the algorithm. In such a situation, it seems more important to effectively search the solution space and to quickly find an approximate solution (in practice, it allows for a more accurate estimation of the ranges of parameter variability) than striving at all costs to find the global optimum, which in the case of the calibration inverse problem, is virtually impossible.

3. An important parameter for evaluating the effectiveness of the algorithm is its operation time, necessary to obtain a satisfactory result which in the case of the inverse calibration problem is reflected in the number of the objective function determination. It must be noted that in case of problem solving, the calculation of the objective function infers launching simulation runs for the values of optimization parameters determined by the algorithm. Depending on the degree of model complexity (number of blocks of the model, applied model of the reservoir fluid), the duration of a single simulation ranges from a dozen to several dozen minutes and in extreme cases can range up to several hours in length.

Please cite as: Nafta-Gaz 2015, no. 11, pp. 870-876, DOI: 10.18668/NG2015.11.09

Article contributed to the Editor 31.08.2015. Approved for publication 9.10.2015.

The article is the result of research conducted in connection with the project: The integrated reservoir engineering model for exploitation of shale gas deposits, co-funded by the National Centre for Research and Development as part of the BLUE GAS POLISH SHALE GAS. Contract No. BG1/IRES/13.

\section{Literature}

[1] Bonabeau B., Dorigo M., Theraukaz G.: Inspiration for optimization from social insect behavior. Nature 2000, vol. 406, no. 6791, pp. 39-42.

[2] Dean S. Oliver, Albert C. Reynolds, Ning Liu: Inverse Theory for Petroleum Reservoir Characterization and History Matching: Cambridge University Press, May 2008.

[3] Goda T., Sato K.: History matching with iterative Latin hypercube samplings and parameterization of reservoir heterogeneity. Journal of Petroleum Science and Engineering 2014, vol. 114, pp. 61-73.

[4] Kathrada M.: Uncertainty evaluation of reservoir simulation models using particle swarms and hierarchical clustering. $\mathrm{PhD}$ thesis, Institute of Petroleum Engineering, Heriot Watt University, Edinburgh 2009.

[5] Letkowski P.: Zastosowanie algorytmu mrowkowego w procesie kalibracji symulacyjnego modelu zlozowego. Nafta-Gaz 2012, no. 2, pp. 98-104.
[6] Letkowski P.: Zastosowanie hybrydowej metody optymalizacji rojem czastek $w$ procesie automatycznej kalibracji modeli zlozowych. Nafta-Gaz 2014, no. 11, pp. 784-793.

[7] Mohamed L., Christie M., Demyanov V.: Comparison of stochastic sampling algorithms for uncertainty quantification. SPE 119139. SPE Reservoir Simulation Symposium, Woodlands, Texas 2-4 February 2009.

[8] Nelder J. A., Mead R.: A simplex method for function minimization. The Computer Journal 1965, 7, pp. 308-313.

[9] For further reading, see: Basic elements of a reservoir characterization study. PetroWiki - published by SPE International; http://petrowiki.org/Basic_elements_of_a_reservoir_characterization_study (access on: 15.08.2015).

[10] Pakiet Eclipse 300, Release 2010.1, 2014.1 firmy GeoQuest, Schlumberger.

[11] Yang X.-S., Deb S.: Cuckoo search via Lévy flights. Proceedings of the IEEE World Congress on Nature \& Biologically Inspired Computing (NaBIC) 2009, pp. 201-214.

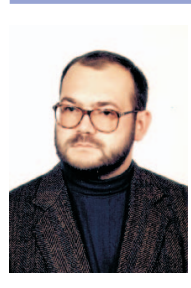

Dr. Eng. Piotr ŁĘTKOWSKI PhD

Assistant Professor

Department of Hydrocarbon Deposits and UGS

Facilities Simulation

Oil and Gas Institute - National Research Institute

ul. Lubicz 25 A, 31-503 Kraków

E-mail:piotr.letkowski@inig.pl

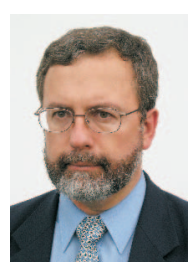

Dr. Wiesław SZOTT PhD.

Assistant Professor

Head of the Department of Hydrocarbon Deposits and UGS Facilities Simulation

Oil and Gas Institute - National Research Institute

ul. Lubicz 25 A, 31-503 Kraków

E-mail: wieslaw.szott@inig.pl 